\title{
Características de carcaça de bovinos de diferentes grupos genéticos, castrados e não-castrados, em fase de terminação'
}

\section{Andréa Vittori ${ }^{2}$, Augusto César de Queiroz ${ }^{3}$, Flávio Dutra de Resende ${ }^{4}$, Antonio Gesualdi Júnior ${ }^{5}$, Guilherme Fernando Alleoni ${ }^{6}$, Alexander George Razook ${ }^{7}$, Leopoldo Andrade de Figueiredo $^{7}$, Ana Cristina Ladeira de Souza Gesualdi ${ }^{8}$}

\author{
1 Parte da tese de Doutorado da primeira autora realizada na APTA - SP e UFV - MG. \\ 2 Doutora em Zootecnia. \\ ${ }^{3}$ Departamento de Zootecnia - UFV. \\ ${ }^{4}$ APTA Regional Alta Mogiana, Av. Rui Barbosa s/rP, Colina - SP, CEP: 14770-000. \\ 5 TECNORTE, Av. Alberto Lamego, 2000, Campos dos Goytacazes - RJ, CEP: 28013-602. \\ 6 Instituto de Zootecnia, Nova Odessa-SP. \\ 7 Instituto de Zootecnia, CAPTA Bovinos de Corte, Sertãozinho - SP. Bolsista do CNPq. \\ ${ }^{8}$ Doutoranda em Zootecnia - LZNA/UENF, Campos dos Goytacazes - RJ, CEP: 28013-602.
}

RESUMO - Analisaram-se as características físicas das carcaças e dos cortes primários de 86 bovinos (12 Gir, 20 Guzerá, 20 Nelore e 20 Caracu selecionados para peso aos 378 dias de idade e 14 Nelore não-selecionados - controle), castrados e nãocastrados, com peso médio inicial de $329 \mathrm{~kg}$ e 20 meses de idade. O volumoso utilizado na dieta ( $14,8 \%$ de PB) foi a silagem de milho, fornecida na relação volumoso:concentrado 60:40 (\%MS). O delineamento experimental utilizado foi o inteiramente casualizado, em esquema fatorial 5 x 2 (grupos genéticos x condição sexual). Os animais não-castrados apresentaram carcaças mais pesadas, com maior rendimento, maior proporção de tecido muscular, porém com espessura de gordura subcutânea semelhante à dos castrados. Os animais da raça Caracu foram mais tardios, com maior deposição de tecido muscular, menor deposição de gordura e menor proporção de traseiro especial quando comparados aos das demais raças. Os animais zebuínos selecionados produziram carcaças mais pesadas que os Nelore não-selecionados. Entre os zebuínos, o maior peso de carcaça quente foi obtido nos animais Nelore selecionados $(287 \mathrm{~kg})$, sendo semelhante ao peso registrado para os Caracu $(299 \mathrm{~kg})$. Os grupos genéticos Nelore e Gir apresentaram os maiores rendimentos de carcaça quente $(57,83 ; 56,82$ e 57,26\%, respectivamente). Os maiores comprimentos de carcaça $(134 \mathrm{~cm})$ foram obtidos nos animais da raça Caracu e os menores $(118,67 \mathrm{~cm})$ nos Nelore não-selecionados. A área de olho-de-lombo foi maior nos animais Caracu que nos zebuínos. Com exceção dos animais Gir, ocorreu o inverso para a gordura subcutânea. A seleção resultou em carcaças mais pesadas na raça Nelore e, quanto à condição sexual, os bovinos não-castrados apresentaram acabamento de gordura de cobertura adequado ao mercado.

Palavras-chave: cortes primários, rendimento de carcaça

\section{Carcass traits of finishing steers and bulls from different genetic groups}

\begin{abstract}
The objective of this trial was to investigate the physical characteristics of carcasses and primary cuts of 86 steers and bulls averaging $329 \mathrm{~kg}$ of body weight and 20 months of age. Twelve Gir, 20 Nellore, 20 Guzerá, and 20 Caracu all from herds that genetically selected for weight gain at 378 days of age and 14 non-genetically improved Nellore (control) were used in this study. Corn silage was used as the forage portion of the diet in a 60:40 (\% DM) forage to concentrate ratio. A completely randomized design with a $5 \times 2$ factorial arrangement of treatments (genetic group and sexual condition) was used. Bulls had carcasses with greater weight, yield, and proportion of muscular tissue but similar subcutaneous fat thickness compared to steers. Caracu showed a slower development but greater muscular tissue deposition and less fat deposition resulting in higher proportion of beef round compared to the remaining breeds. The genetically improved Zebu had heavier carcasses than the non-genetically improved Nellore. The greatest hot carcass weight within Zebu was observed on the genetically improved Nellore $(287 \mathrm{~kg}$ ) and was similar to that found on Caracu $(299 \mathrm{~kg})$. Genetically and non-genetically improved Nellore and Gir had the highest yields of hot carcass (57.83, 56.82 and 57.26\%, respectively). Caracu showed the greatest carcass length $(134 \mathrm{~cm})$ while non-geneticallyimproved Nellore the lowest $(118.67 \mathrm{~cm})$. The rib eye area was greater on Caracu than Zebu whereas the opposite was observed for subcutaneous fat thickness with the exception of Gir. Within the genetically improved animals, Nellore had the greatest carcass weight and within sexual condition, bulls showed finishing covering fat that fulfills the market requirements.
\end{abstract}

Key Words: carcass yield, primary cuts 


\section{Introdução}

O desempenho de bovinos na fase de terminação, o rendimento de carcaça e a qualidade da carne dependem da combinação de fatores como raça e alimentação, que afetam ainda a precocidade no acabamento do animal (Nardon, 1998). Neste aspecto, o confinamento é uma ferramenta que possibilita o abate de animais jovens e bem acabados, proporcionando, em geral, carcaças e carne de melhor qualidade (Costa et al., 2005).

Segundo Luchiari Filho (2000), uma carcaça bovina de boa qualidade e bom rendimento deve apresentar relação adequada entre as partes que a compõem (máximo de músculo, mínimo de ossos e quantidade adequada de gordura) para assegurar ao produto condições mínimas de manuseio e palatabilidade.

O estudo da carcaça dos animais deve ter como finalidade avaliar parâmetros mensuráveis e que estão relacionados a seus aspectos qualitativos e quantitativos (Müller, 1987). Um exemplo é o estudo de Crouse \& Dikeman, (1976), que avaliaram a espessura de gordura subcutânea, a área do músculo Longissimus dorsi, a porcentagem de gordura interna, o peso da carcaça e o marmoreio, para, posteriormente, desenvolverem a equação de regressão múltipla que permitiu explicar 79,2\% da variação na porcentagem de carne.

Outro as pecto é que, no estudo das carcaças bovinas, utiliza-se o seu rendimento para expressar a relação percentual entre o peso da carcaça e o peso do animal. Entretanto, segundo Gesualdi Jr. et al. (2000), a estimativa deste rendimento deve ser usada em conjunto com a dos cortes primários para complementar a avaliação do desempenho do animal durante seu desenvolvimento, pois o valor do rendimento de carcaça é influenciado pelo peso vivo do animal, que, por sua vez, é alterado pelo peso do conteúdo do trato gastrintestinal (Owens et al., 1993), pelo grupo genético e pela maturidade do animal, assim como pelos pesos das partes não-integrantes da carcaça (Jorge et al., 1999).

Os cortes básicos de carcaças bovinas no Brasil são o dianteiro com cinco costelas, a ponta-de-agulha e o traseiro especial (Silva et al. 2002). Economicamente, seria desejável maior rendimento do traseiro especial em relação aos outros cortes, pois nele se encontram as partes nobres com maior valor comercial da carcaça. Em animais machos, isso só pode ser alcançado por meio do abate em idade precoce, para evitar os efeitos do dimorfismo sexual, ou por meio da castração, para suprimir os hormônios sexuais masculinos e, em algumas situações, produzir animais com maior porcentagem de traseiro.
A condição sexual também influencia a composição do ganho de peso e a da carcaça (Resende 2001). Animais de sexos diferentes atingem o ponto de abate (mesmo grau de acabamento da carcaça) em pesos ou idades diferentes (Berg \& Butterfield, 1976).

Segundo Silva (2000), a prática da castração de animais para abate é tradicionalmente realizada no Brasil por motivos econômicos e de aceitação do consumidor. Muitos frigoríficos exigem a castração dos animais alegando que esse procedimento favorece a uniformidade e a qualidade da carcaça, além da conservação e do aspecto da carne. Quanto ao desempenho, em geral, os resultados indicam que animais não-castrados crescem mais rápido, utilizam alimentos mais eficientemente e produzem carcaças com maior porcentagem de carne comercializável e com menos gordura, enquanto os castrados apresentam carcaça com carne mais macia. Apesar de todo o conhecimento acerca dos efeitos da castração, a técnica ainda tem sido objeto de estudos (Pádua et al., 2004), pois, talvez, os resultados sejam afetados, entre outros fatores, pelos sistemas de terminação e manejo alimentar.

Neste estudo, objetivou-se avaliar as características físicas das carcaças e dos cortes primários de animais de diferentes grupos genéticos (Gir, Guzerá, Nelore e Caracu submetidos à seleção para peso aos 378 dias de idade e Nelore não-selecionados, castrados e não-castrados).

\section{Material e Métodos}

O experimento foi realizado na Estação Experimental de Zootecnia de Colina - Instituto de Zootecnia, Colina-SP, localizada em altitude média de $589 \mathrm{~m}$, latitude sul de $20^{\circ} 43^{\prime} 5^{\prime \prime}$ e longitude oeste de $48^{\circ} 32^{\prime} 38^{\prime}$ '. O clima é classificado, segundo Köppen, como $A W$, caracterizado como tropical úmido, com estação chuvosa no verão (outubro a março) e seca no inverno (abril a setembro). A temperatura média do mês mais quente é de $22^{\circ} \mathrm{C}$ e a do mês mais frio é de $18^{\circ} \mathrm{C}$.

Foram utilizados 86 animais (12 Gir, 20 Guzerá, 20 Nelore e 20 Caracu selecionados para peso aos 378 dias de idade (P378) e 14 Nelore não-selecionados, amostrados ao término da prova de ganho de peso de 1999) com 20 meses de idade e peso vivo inicial de $329 \mathrm{~kg}$, provenientes da 18 a progênie realizada pelo Instituto de Zootecnia de Sertãozinho-SP. Do total de animais de cada grupo genético, metade foi castrada logo após o final da prova de ganho de peso, em outubro de 1999. O período de adaptação teve duração de 28 dias e, nesta etapa, todos os animais receberam a ração utilizada no período experimental. Após o período de adaptação, o confinamento foi iniciado em abril de 2000, quando os 
animais foram distribuídos aos pares, por grupo genético e condição sexual, aleatoriamente em baias contendo cochos cobertos e piso calçado.

A dieta experimental continha $14,80 \%$ de $\mathrm{PB}$, com proporção volumoso:concentrado 60:40 na MS. A ração experimental (Tabela 1) foi calculada com base nas exigências nutricionais propostas pelo NRC (1996) para ganho de peso vivo estimado de $1,0 \mathrm{~kg} /$ animal/dia.

Os alimentos foram fornecidos duas vezes ao dia, às 7 e 16h. A silagem de milho foi retirada do silo pouco antes do horário de fornecimento e misturada ao concentrado. As quantidades oferecidas (pesadas diariamente) foram calculadas para permitir aproximadamente 5\% de sobras. Semanalmente, foram coletadas amostras de silagem, concentrado e sobras, que foram secas em estufa de ventilação forçada, a $55^{\circ} \mathrm{C}$, compostas por período de 28 dias, sendo trituradas em moinho de facas com peneira de $1 \mathrm{~mm}$, identificadas, embaladas e acondicionadas para as análises químicas posteriores.

Os níveis de nutrientes dos componentes da ração são apresentados na Tabela 2.

Tabela 1 - Proporção dos ingredientes na mistura do concentrado

Table 1 - Ingredient composition of the concentrate mix (\%)

\begin{tabular}{lc}
\hline $\begin{array}{l}\text { Ingrediente } \\
\text { Ingredient }\end{array}$ & $\begin{array}{c}\% \text { do ingrediente } \\
\% \text { of ingredient }\end{array}$ \\
\hline Fubá de milho (\%) (Corn meal, \%) & 76,70 \\
Farelo de algodão (\%)(Cottonseed meal, \%) & 19,00 \\
Uréia (\%)(Urea, \%) & 1,8 \\
Calcário calcítico (\%)(Limestone, \%) & 1,50 \\
Mistura mineral (\%)(Mineral mix, \%) & 1,00 \\
\hline
\end{tabular}

Tabela 2 - Teores de MS MS, MO, PB, FDN, EE e CIN do concentrado e da silagem de milho

Table 2 - Contents of DM, OM, CP, NDF, EE and ash of concentrate and corn silage

\begin{tabular}{|c|c|c|c|c|}
\hline $\begin{array}{l}\text { Nutriente } \\
\text { Nutrient }\end{array}$ & $\begin{array}{l}\text { Concentrado } \\
\text { Concentrate }\end{array}$ & $\begin{array}{c}\text { Farelo de } \\
\text { algodão } \\
\text { Cottonseed meal }\end{array}$ & $\begin{array}{c}\text { Fubá de } \\
\text { milho } \\
\text { Corn meal }\end{array}$ & $\begin{array}{l}\text { Silagem de } \\
\text { milho } \\
\text { Corn silage }\end{array}$ \\
\hline MS (\%) & 81,21 & 81,87 & 79,45 & 31,03 \\
\hline $\begin{array}{l}D M(\%) \\
\mathrm{MO}^{1}\end{array}$ & 96,75 & 94,61 & 98,86 & 95,64 \\
\hline $\begin{array}{l}O M \\
\mathrm{~PB}^{1} \\
C P\end{array}$ & 24,60 & 40,98 & 10,94 & 8,26 \\
\hline $\mathrm{FDN}^{1}$ & 17,31 & 33,23 & 12,11 & 47,85 \\
\hline $\begin{array}{l}N D F \\
\mathrm{EE}^{1} \\
\mathrm{CIN}^{1} \\
\text { Ash }\end{array}$ & $\begin{array}{l}1,30 \\
3,25\end{array}$ & $\begin{array}{l}0,62 \\
5,39\end{array}$ & $\begin{array}{l}0,28 \\
1,14\end{array}$ & $\begin{array}{l}2,81 \\
4,36\end{array}$ \\
\hline
\end{tabular}

Nas amostras dos alimentos fornecidos e das sobras, foram determinados os teores de MS, MO, PB, FDN, CIN e EE, conforme descrito por Van Soest et al. (1991) e Silva \& Queiroz (2002).

Ao início do experimento e a intervalos de 28 dias, os animais foram pesados em jejum completo de 18 horas, sendo monitoradas a espessura de gordura de cobertura e a área de olho-de-lombo, por meio de ultra-sonografia em tempo real. À medida que a espessura de gordura de cobertura dos animais, por baia, atingiu o valor de $4 \mathrm{~mm}$, os animais foram abatidos. O peso vivo médio de abate foi $449 \mathrm{~kg}$ para os animais Gir, 469,8 kg para os Guzerá, 406,2 kg para os Nelore não-selecionado, 495,6 kg para os Nelore selecionados e $533,5 \mathrm{~kg}$ para os Caracu.

Os animais foram abatidos, após jejum completo (18 horas) e pesagem, no Frigorífico Minerva, no município de Barretos-SP, conforme procedimento usual do frigorífico. Depois de contidos, os animais foram abatidos por concussão cerebral e, em seguida, foram suspensos para posterior sangria por secção da veia jugular. As gorduras pélvica e renal e as meias-carcaças quentes foram pesadas e, em seguida, foram mantidas por 24 horas em câmara de resfriamento para nova pesagem. Após o resfriamento, realizaram-se as medições de comprimento e profundidade nas meias-caraças direitas, que foram separadas em traseiro especial, ponta-de-agulha e dianteiro (cinco costelas), que, por sua vez, foram d esossados para cálculo de seus rendimentos.

Nas meias-carcaças esquerdas, também após o resfriamento por 24 horas, foram determinadas a espessura da gordura de cobertura e a área de olho-de-lombo, no músculo Longissimus dorsi, na região da 12 -13 e 13 costelas, retirando-se o corte entre a $9 \underline{a}$ e $11 \underline{a}$ costelas (seção HH), segundo metodologia descrita por Hankins \& Howe (1946), para separação física dos músculos, da gordura e dos ossos. Esses componentes foram moídos separadamente retirando-se amostras individuais, que foram devidamente armazenadas, identificadas, liofilizadas, moídas com gelo seco, embaladas e acondicionadas em freezer.

O delineamento experimental adotado foi o inteiramente casualizado em esquema fatorial 5 x 2 (grupo genético $\mathrm{x}$ sexo). Os dados foram submetidos à análise de variância utilizando-se o procedimento GLM do SAS (1989). As médias foram comparadas pelo teste de Diferença Mínima Significativa, adotando-se $\alpha=0,05$.

Os dados foram analisados segundo o modelo estatístico: $\mathrm{Y}_{\mathrm{ijk}}=\mu+\alpha_{\mathrm{i}}+\beta_{\mathrm{j}}+(\alpha \beta)_{\mathrm{ij}}+\varepsilon_{\mathrm{ijk}}$

em que: $\mathrm{Y}_{\mathrm{ijk}}=$ variável resposta referente ao animal $\mathrm{k}$, do grupo genético i e do sexo $j ; \mu=$ constante geral; $\alpha_{i}=$ efeito do grupo genético $i ; \beta_{j}=$ efeito do sexo $j ; \alpha \beta_{i j}=$ efeito da 
interação do grupo genético i com o $\operatorname{sexo} \mathrm{j} ; \varepsilon_{\mathrm{ijk}}=$ erro aleatório, suposto NID $\left(0, \sigma^{2}\right)$; i = 1 - Gir, 2 - Guzerá, 3 - Nelore não-selecionado, 4 - Nelore selecionado, 5 - Caracu; $=1$ - castrado, 2 - não-castrado; e k = variável.

\section{Resultados e Discussão}

Não houve interação de grupo genético e condição sexual para nenhum dos fatores estudados $(\mathrm{P}>0,05)$. Houve efeito de grupo genético e condição sexual para pesos de carcaça quente (PCQ) e fria (PCF) e rendimentos da carcaça quente $(\mathrm{RCQ})$ e fria $(\mathrm{RCF})(\mathrm{P}<0,05)$, conforme demonstrado na Tabela 3.

Os animais Caracu e Nelore selecionados apresentaram os maiores PCQ e PCF, enquanto os Nelore não-selecionados apresentaram os menores valores para estas características $(\mathrm{P}<0,05)$. Em termos numéricos, isto significou carcaças $24,3 \%$ mais pesadas para os Nelore selecionados em relação aos não-selecionados.

Como os Nelore não-selecionados não foram selecionados para ganho de peso, já era esperado que apresentassem menores pesos de carcaça, o que reflete o desempenho inferior dos zebuínos utilizados décadas atrás, antes dos modernos programas de melhoramento genético implantados no Brasil. Essas diferenças também foram observadas por Nardon (1998), que encontrou PCQ de 289 e $259 \mathrm{~kg}$ para os grupos Nelore selecionados e não-selecionados, respectivamente.

Quanto ao RCQ e RCF, houve superioridade para os grupos genéticos Nelore selecionado, Gir e Nelore nãoselecionado e menores rendimentos para os Caracu e Guzerá, sendo que os Nelore não-selecionados apresentaram rendimentos também semelhantes aos dos animais Caracu ( $\mathrm{P}<0,05)$. Estes resultados corroboram os de Nardon (1998), que trabalhou com os mesmos grupos genéticos utilizados neste estudo. Isso pode indicar diferenças na composição corporal dos animais, das partes que normalmente não compõem as carcaças e que, devido ao processo de abate, não puderam ser analisadas, como peso de cabeça, pés, couro e órgãos internos, o que provavelmente levou a um menor RCQ e RCF dos grupos Caracu e Guzerá.

Os valores de RCQ apresentados pelos animais Nelore selecionados $(57,83 \%)$ e Nelore não-selecionados $(56,82 \%)$ foram inferiores aos encontrados por Silva et al. (2002), que verificaram 59,6\% de RCQ para animais Nelore e foram semelhantes aos de Costa et al. (2005), que relataram 57,4\%, porém, utilizando novilhos anelorados. Nos dois trabalhos, os autores forneceram dietas com nível de concentrado próximo de $40 \%$. As diferenças encontradas na literatura podem ser explicadas pelo fato de que o valor do rendimento de carcaça é influenciado, entre outros fatores, pelo peso vivo de abate e pelo peso das partes não-integrantes da carcaça (Jorge et al., 1999), sendo que o peso destas partes, dentro de certos limites, tende a variar de acordo com as diferentes condições de abate e a coleta de dados.

Os animais não-castrados tiveram carcaças mais pesadas, no mesmo ponto de acabamento, com maiores rendimentos, o que era esperado, pois nos animais não-castrados há a atuação hormonal da testosterona, que aumenta a síntese protéica e reduz a de gordura. A presença dos hormônios androgênicos, principalmente a testosterona, proporciona melhor anabolismo do nitrogênio. Morgan et al. (1993) constataram que animais castrados possuem massa de proteína muscular esquelética menor que a dos

Tabela 3 - Médias de quadrados mínimos dos pesos de carcaça quente (PCQ, em kg) e de carcaça fria (PCF, em kg), dos rendimentos de carcaça quente (RCQ, em \% carcaça) e de carcaça fria (RCF, em \% carcaça), da quebra ao resfriamento (QR, em \%) e das gorduras renal e pélvica (GRP, em \%), em relação ao peso da carcaça, de animais de diferentes grupos genéticos e condições sexuais (castrado e não-castrado)

Table 3 - Least square means of hot carcass weight ( $\mathrm{HCW}, \mathrm{kg}$ ), cold carcass weight (CCW, $\mathrm{kg}$ ), hot carcass yield (HCY, \% carcass), cold carcass yield (CCY, in \% carcass), cooling loss (CL, \%), and pelvic and kidney fat (PKF), as proportion or carcass weight, of animals from different genetic groups and sexual condition (steers and bulls)

\begin{tabular}{|c|c|c|c|c|c|c|c|c|}
\hline \multirow[t]{2}{*}{ Item } & \multicolumn{5}{|c|}{$\begin{array}{l}\text { Grupo genético } \\
\text { Genetic group }\end{array}$} & \multicolumn{2}{|c|}{$\begin{array}{l}\text { Condição sexual } \\
\text { Sexual condition }\end{array}$} & \multirow[t]{2}{*}{ CV (\%) } \\
\hline & $\begin{array}{l}\text { Gir } \\
\text { Gir }\end{array}$ & $\begin{array}{l}\text { Guzerá } \\
\text { Guzera }\end{array}$ & $\begin{array}{c}\text { Nelore não-selecionado } \\
\text { Ordinary Nellore }\end{array}$ & $\begin{array}{c}\text { Nelore selecionado } \\
\text { Genetically improved Nellore }\end{array}$ & $\begin{array}{l}\text { Caracu } \\
\text { Caracu }\end{array}$ & $\begin{array}{l}\text { Castrado } \\
\text { Steer }\end{array}$ & $\begin{array}{c}\text { Não-castrado } \\
\text { Bull }\end{array}$ & \\
\hline $\mathrm{PCQ}^{1}(\mathrm{HCW})$ & $257^{\mathrm{b}}$ & $259^{\mathrm{b}}$ & $231^{\mathrm{c}}$ & $287^{\mathrm{a}}$ & $299^{a}$ & $249^{b}$ & $284^{\mathrm{a}}$ & 7,79 \\
\hline $\operatorname{RCQ}^{1}(H C Y)$ & $57,26^{\mathrm{a}}$ & $55,19^{\mathrm{c}}$ & $56,82^{\mathrm{ab}}$ & $57,83^{\mathrm{a}}$ & $55,99^{\mathrm{bc}}$ & $55,64^{\mathrm{b}}$ & $57,60^{\mathrm{a}}$ & 2,62 \\
\hline $\mathrm{PCF}^{1}(C C W)$ & $254^{\mathrm{b}}$ & $256^{\mathrm{b}}$ & $229^{c}$ & $284^{\mathrm{a}}$ & $296^{\mathrm{a}}$ & $246^{\mathrm{b}}$ & $282^{\mathrm{a}}$ & 7,87 \\
\hline $\mathrm{RCF}^{1}(C C Y)$ & $56,59^{\mathrm{ab}}$ & $54,56^{\mathrm{d}}$ & $56,27^{\mathrm{bc}}$ & $57,32^{\mathrm{a}}$ & $55,43^{\mathrm{c}}$ & $55,05^{\mathrm{b}}$ & $57,02^{\mathrm{a}}$ & 2,58 \\
\hline $\mathrm{QR}^{1}(C L)$ & $1,17^{\mathrm{a}}$ & $1,13^{\mathrm{a}}$ & $0,97^{\mathrm{a}}$ & $0,89^{\mathrm{a}}$ & $1,00^{\mathrm{a}}$ & $1,06^{\mathrm{a}}$ & $1,00^{\mathrm{a}}$ & 53,72 \\
\hline $\mathrm{GRP}^{1}(P K F)$ & $0,99^{\mathrm{a}}$ & $0,96^{\mathrm{a}}$ & $1,01^{\mathrm{a}}$ & $0,97^{\mathrm{a}}$ & $1,11^{\mathrm{a}}$ & $1,09^{\mathrm{a}}$ & $0,93^{\mathrm{b}}$ & 26,72 \\
\hline
\end{tabular}

${ }^{1}$ Médias na linha, dentro de grupo genético e condição sexual, seguidas por letras diferentes, são diferentes ( $\left.\mathrm{P}<0,05\right)$ pelo teste de Diferença Mínima Significativa (DMS).

${ }^{1}$ Means in a row, within genetic group and sexual condition, followed by different letters, differ $(P<0.05)$ by Least Significance Difference test (LSD). 
não-castrados, indicando maior índice de degradação des sa proteína. Estes autores observaram também maior excreção de creatinina nos touros, indicando maior massa muscular nestes animais, com menor degradação de proteína por unidade de massa muscular.

Este resultado foi confirmado quando se analisou a variável gordura renal e pélvica (GRP) (Tabela 3), que foi maior nos animais castrados, aumentando os componentes não-integrantes da carcaça e reduzindo o rendimento. Segundo Luchiari Filho (2000), a GRP pode pesar até mais de $6 \%$ do peso da carcaça.

Não houve diferença para quebra ao resfriamento (QR) quando grupo genético e condição sexual foram considerados. Uma possível explicação para este resultado pode ser o fato de que o critério de abate adotado (4 $\mathrm{mm}$ de espessura de gordura subcutânea) proporcionou o mesmo grau de acabamento em todas as carcaças. Neste caso, considerando que o abate foi realizado em frigorífico comercial e os procedimentos adotados já são padronizados, as carcaças poderiam ter sofrido os efeitos do resfriamento na mesma intensidade, mesmo com o abate ocorrendo em dias diferentes. Trata-se de uma especulação, visto que não se pode confirmar que o resfriamento tenha sido idêntico em dias diferentes.

Na Tabela 4 são representadas as médias de quadrados mínimos das porcentagens dos tecidos muscular (TM), adiposo (TA) e ósseo (TO). Os animais Caracu e Gir tiveram maior porcentagem de TM e menor de TA, demonstrando serem mais tardios quanto à deposição de gordura. Isso indica, especialmente, que a raça Gir, tradicionalmente considerada como de duplo propósito, ou seja, para produção de carne e leite, tem respondido satisfatoriamente à seleção, apresentando alta porcentagem de tecido muscular, desejável nas raças de corte.
Analisando os grupos de animais, verificou-se que os animais Caracu foram mais tardios e com maior peso à maturidade que aqueles dos demais grupos genéticos. Portanto, para que atinjam o mesmo grau de acabamento dos animais das raças zebuínas, devem ser abatidos com peso mais elevado. As raças de tamanho grande e musculatura grossa têm maiores taxas de crescimento, que implicam maior ganho de peso por dia (Hammack, 2001), mas são mais tardias para acúmulo mínimo de gordura na carcaça.

As relações músculo:osso e músculo:gordura apresentaram o mesmo comportamento, sendo maiores para os animais Caracu e Gir e menores para os Nelore selecionados, os Nelore não-selecionados e os Guzerá, que não diferiram entre si, refletindo uma participação decrescente do tecido muscular na carcaça dos animais dessas raças, uma vez que não houve influência do grupo genético sobre a porcentagem de osso na carcaça.

Nas variáveis TM, TA, RMO e RMG, também ficou evidenciado o efeito da ação hormonal da testosterona, uma vez que os animais não-castrados apresentaram maiores TM, RMO e RMG que os castrados, culminando maior participação do tecido muscular na carcaça.

Quanto aos cortes primários, houve efeito da condição sexual para todas as variáveis analisadas (Tabela 5). Os animais não-castrados apresentaram maiores pesos de dianteiro (D), ponta-de-agulha (PA) e traseiro especial (TE), refletindo o maior peso vivo de abate e de carcaça quente deste grupo em relação ao dos castrados. Porém, quando os cortes primários foram expressos em porcentagem da carcaça, observou-se maior rendimento de dianteiro (RD) e menor de traseiro especial (RTE) nos animais nãocastrados, indicativo do dimorfismo sexual nestes animais. Considerando que os cortes comerciais mais nobres se

Tabela 4 - Médias de quadrados mínimos das porcentagens dos tecidos muscular (TM), adiposo (TA) e ósseo (TO) e relações músculo:osso (RMO) e músculo:gordura (RMG) dos animais de diferentes grupos genéticos e condições sexuais (castrado e não-castrado)

Table 4 - Least square means of the percentages of bone (BP), muscle (MP), and adipose tissue (AP) and the ratios of muscle:bone (MBR) and muscle:adipose tissue (MAR) of animals from different genetic groups and sexual condition (steers and bulls)

\begin{tabular}{|c|c|c|c|c|c|c|c|c|}
\hline \multirow[t]{2}{*}{ Item } & \multicolumn{5}{|c|}{$\begin{array}{l}\text { Grupo genético } \\
\text { Genetic group }\end{array}$} & \multicolumn{2}{|c|}{$\begin{array}{l}\text { Condição sexual } \\
\text { Sexual condition }\end{array}$} & \multirow[t]{2}{*}{$\mathrm{CV}(\%)$} \\
\hline & $\begin{array}{l}\text { Gir } \\
\text { Gir }\end{array}$ & $\begin{array}{c}\text { Guzerá } \\
\text { Guzera }\end{array}$ & $\begin{array}{c}\text { Nelore não-selecionado } \\
\text { Ordinary Nellore }\end{array}$ & $\begin{array}{c}\text { Nelore selecionado } \\
\text { Genetically improved Nellore }\end{array}$ & $\begin{array}{l}\text { Caracu } \\
\text { Caracu }\end{array}$ & $\begin{array}{l}\text { Castrado } \\
\text { Steer }\end{array}$ & $\begin{array}{c}\text { Não-castrado } \\
\text { Bull }\end{array}$ & \\
\hline $\mathrm{TM}^{1}(M P)$ & $60,37^{\mathrm{a}}$ & $57,66^{\mathrm{b}}$ & $56,84^{\mathrm{b}}$ & $56,88^{\mathrm{b}}$ & $61,24^{\mathrm{a}}$ & $56,96^{\mathrm{b}}$ & $60,24^{\mathrm{a}}$ & 3,71 \\
\hline $\mathrm{TA}^{1}(A P)$ & $24,27^{\mathrm{b}}$ & $26,60^{\mathrm{a}}$ & $27,74^{\mathrm{a}}$ & $27,58^{\mathrm{a}}$ & $23,61^{\mathrm{b}}$ & $27,42^{\mathrm{a}}$ & $24,50^{\mathrm{b}}$ & 10,46 \\
\hline $\mathrm{TO}^{1}(B P)$ & $15,36^{\mathrm{a}}$ & $15,74^{\mathrm{a}}$ & $15,42^{\mathrm{a}}$ & $15,55^{\mathrm{a}}$ & $15,15^{\mathrm{a}}$ & $15,62^{\mathrm{a}}$ & $15,26^{\mathrm{a}}$ & 8,02 \\
\hline $\mathrm{RMO}^{1}(M B R)$ & $3,24^{\mathrm{a}}$ & $2,93^{\mathrm{b}}$ & $2,94^{\mathrm{b}}$ & $2,96^{\mathrm{b}}$ & $3,37^{\mathrm{a}}$ & $2,92^{\mathrm{b}}$ & $3,26^{\mathrm{a}}$ & 12,05 \\
\hline $\mathrm{RMG}^{1}(M A R)$ & $2,21^{\mathrm{a}}$ & $1,85^{\mathrm{b}}$ & $1,71^{b}$ & $1,74^{\mathrm{b}}$ & $2,36^{\mathrm{a}}$ & $1,75^{\mathrm{b}}$ & $2,20^{\mathrm{a}}$ & 21,15 \\
\hline
\end{tabular}

${ }^{1}$ Médias na linha, dentro de grupo genético e condição sexual, seguidas por letras diferentes, são diferentes $(P<0,05)$ pelo teste de Diferença Mínima Significativa (DMS).

${ }^{1}$ Means in a row, within genetic group and sexual condition, followed by different letters, differ $(P<0.05)$ by Least Significance Difference test (LSD). 
Tabela 5 - Médias de quadrados mínimos do peso (em $\mathrm{kg}$ ) do dianteiro (D), da ponta-de-agulha (PA) e do traseiro especial (TE) e do rendimento (em \%) de dianteiro (RD) e traseiro especial (RTE) de animais de diferentes grupos genéticos e condições sexuais (castrado e não-castrado)

Table 5 - Least square means of the weights (kg) of primary cuts: forequarter (F), flank with ribs (FR) and beef round (BR) and yields of forequarter (YF) and beef round (YBR) of animals from different genetic groups and sexual condition (steers and bulls)

\begin{tabular}{|c|c|c|c|c|c|c|c|c|}
\hline \multirow[t]{2}{*}{ Item } & \multicolumn{5}{|c|}{$\begin{array}{l}\text { Grupo genético } \\
\text { Genetic group }\end{array}$} & \multicolumn{2}{|c|}{$\begin{array}{l}\text { Condição sexual } \\
\text { Sexual condition }\end{array}$} & $\mathrm{CV}(\%)$ \\
\hline & $\begin{array}{l}\text { Gir } \\
\text { Gir }\end{array}$ & $\begin{array}{l}\text { Guzerá } \\
\text { Guzera }\end{array}$ & $\begin{array}{c}\text { Nelore não-selecionado } \\
\text { Ordinary Nellore }\end{array}$ & $\begin{array}{c}\text { Nelore selecionado } \\
\text { Genetically improved Nellore }\end{array}$ & $\begin{array}{l}\text { Caracu } \\
\text { Caracu }\end{array}$ & $\begin{array}{l}\text { Castrado } \\
\text { Steer }\end{array}$ & $\begin{array}{c}\text { Não-castrado } \\
\text { Bull }\end{array}$ & \\
\hline $\mathrm{D}^{1}(F)$ & $52,93^{\mathrm{b}}$ & $51,75^{\mathrm{b}}$ & $46,98^{\mathrm{b}}$ & $58,06^{\mathrm{a}}$ & $59,60^{\mathrm{a}}$ & $48,34^{\mathrm{b}}$ & $59,38^{\mathrm{a}}$ & 8,97 \\
\hline $\mathrm{PA}^{1}(F R)$ & $15,08^{\mathrm{c}}$ & $16,74^{\mathrm{b}}$ & $14,08^{\mathrm{c}}$ & $17,81^{\mathrm{b}}$ & $19,80^{\mathrm{a}}$ & $15,93^{\mathrm{b}}$ & $17,47^{\mathrm{a}}$ & 11,25 \\
\hline $\mathrm{TE}^{1}(B R)$ & $60,43^{\mathrm{b}}$ & $61,19^{b}$ & $54,57^{\mathrm{c}}$ & $67,95^{\mathrm{a}}$ & $67,26^{\mathrm{a}}$ & $59,37^{\mathrm{b}}$ & $65,19^{\mathrm{a}}$ & 7,29 \\
\hline $\mathrm{RD}^{1}(Y F)$ & $41,07^{\mathrm{a}}$ & $39,86^{\mathrm{a}}$ & $40,48^{\mathrm{a}}$ & $40,28^{\mathrm{a}}$ & $40,53^{\mathrm{a}}$ & $39,10^{\mathrm{b}}$ & $41,79^{\mathrm{a}}$ & 3,48 \\
\hline $\operatorname{RTE}^{1}(Y B R)$ & $47,17^{\mathrm{a}}$ & $47,26^{\mathrm{a}}$ & $47,39^{\mathrm{a}}$ & $47,33^{\mathrm{a}}$ & $45,94^{\mathrm{b}}$ & $48,11^{\mathrm{a}}$ & $45,92^{\mathrm{b}}$ & 2,61 \\
\hline
\end{tabular}

${ }^{1}$ Médias na linha, dentro de grupo genético e condição sexual, seguidas por letras diferentes são diferentes $(P<0,05)$ pelo teste de Diferença Mínima Significativa (DMS).

${ }^{1}$ Means in a row, within genetic group and sexual condition, followed by different letters, differ $(P<0.05)$ by Least Significance Difference test (LSD).

encontram nesta região, neste aspecto, os animais castrados sobressaíram relativamente aos não-castrados.

Não houve diferenças entre os grupos genéticos para o rendimento de dianteiro (Tabela 5). Os valores entre 39,86 e $41,07 \%$ para os rendimentos de dianteiro apresentados pelas raças zebuínas foram próximos aos encontrados por Silva et al. (2002), de 41,4\%, para bovinos Nelore recebendo dietas com $40 \%$ de concentrado. Costa et al. (2005), por sua vez, trabalhando com bovinos anelorados, encontraram valores de 38,4 e 39,5\% para RD nas dietas com 35 e $60 \%$ de concentrado, respectivamente, ou seja, valores próximos aos dos grupos genéticos utilizados neste estudo.

Não houve diferença entre as raças zebuínas para o rendimento de traseiro especial, porém, os valores foram superiores aos dos animais Caracu (Tabela 5), indicando, talvez, a necessidade de esforços para melhoria deste corte nos programas de melhoramento da raça. Os valores entre 47,17 e 47,39\% para RTE nos animais das raças zebuínas foram superiores aos reportados por Silva et al. (2002), que encontraram $44,9 \%$ em animais Nelore recebendo dietas com $40 \%$ de concentrado e foram semelhantes aos $47,0 \%$ encontrados por Cruz et al. (2004), em novilhos Nelore abatidos com $440 \mathrm{~kg}$ de PV alimentados com dietas com $50 \%$ de concentrado.

A ausência de diferenças marcantes para rendimento dos cortes primários encontrada na literatura pode estar relacionada à semelhança nos grupos genéticos, Zebu ou azebuados, e no manejo alimentar adotado nos confinamentos brasileiros, em que a relação volumoso:concentrado é próxima de 50:50.

Quanto aos grupos genéticos, os animais Caracu e Nelore-selecionado tiveram D, PA e TE mais pesados que os das demais raças, refletindo o maior peso vivo de abate.

Segundo Luchiari Filho (2000), é desejável que, em relação ao peso da carcaça, a proporção de traseiro especial fique acima de $48 \%$, a de dianteiro até $39 \%$ e a ponta-deagulha até $13 \%$. Neste estudo, nenhum dos grupos genéticos atingiu esses padrões, embora nos zebuínos tenham sido obtidos valores próximos a 48\% para RTE. Quanto ao sexo, apenas os animais castrados produziram proporção de dianteiro e traseiro especial dentro dos padrões recomendados.

Na Tabela 6 são representadas as médias de quadrados mínimos do comprimento e da profundidade da carcaça direita ( $\mathrm{CC}$ e $\mathrm{PC}$, respectivamente, em $\mathrm{cm}$ ), da área de olhode-lombo (AOL, em cm² e AOLC, em cm²/100 kg de carcaça) e da gordura de cobertura (GC).

Os maiores CC e AOL obtidos nos animais Caracu podem ser atribuídos aos maiores pesos vivos de abate e de carcaça quente. A conformação corporal dos animais,por si só, indica estes resultados, pois possui perfil retilíneo, ligeiramente convexo. É uma raça com características corporais diferentes das dos zebuínos. Entretanto, quando analisada a AOLC, a superioridade dos animais Caracu desapareceu, resultando em maiores valores para os Nelore não-selecionados.

Resende et al. (2000), trabalhando com animais nãocastrados dos mesmos grupos genéticos e provenientes da mesma fazenda daqueles utilizados neste estudo, porém da progênie anterior, também encontraram maiores AOL para a raça Caracu. Os resultados foram superiores inclusive para AOLC. Esses autores também utilizaram o mesmo critério de abate deste estudo. Perotto et al. (2000), trabalhando com várias raças em confinamento e fornecendo uma dieta com relação volumoso:concentrado de 67:33, encontraram o valor de $70 \mathrm{~cm}^{2}$ para AOL em animais Caracu, inferior ao desse trabalho. Entretanto, o PCQ desses animais foi $29 \mathrm{~kg}$ inferior aos dos animais Caracu deste estudo. 
Tabela 6 - Médias de quadrados mínimos do comprimento (CC) e da profundidade da carcaça direita (PC), em cm, da área de olho-delombo (AOL), em $\mathrm{cm}^{2}$, da área de olho-de-lombo $\left(\mathrm{cm}^{2}\right)$ por $100 \mathrm{~kg}$ de carcaça (AOLC) e da gordura de cobertura (GC) (mm) dos animais de diferentes grupos genéticos e condições sexuais (castrado e não-castrado)

Table 6 - Least square means of the length ( $L C, \mathrm{~cm})$ and depth (DC, cm) of the right carcass, rib eye area (REA, cn? ), rib eye area (cní) per $100 \mathrm{~kg}$ of carcass weight (REAC), and back fat thickness (BFT, $\mathrm{mm}$ ) of animals from different genetic groups and sexual condition (steers and bulls)

\begin{tabular}{|c|c|c|c|c|c|c|c|c|}
\hline \multirow[t]{2}{*}{ Item } & \multicolumn{5}{|c|}{$\begin{array}{l}\text { Grupo genético } \\
\text { Genetic group }\end{array}$} & \multicolumn{2}{|c|}{$\begin{array}{l}\text { Condição sexual } \\
\text { Sexual condition }\end{array}$} & \multirow[t]{2}{*}{$\mathrm{CV}(\%)$} \\
\hline & $\begin{array}{l}\text { Gir } \\
\text { Gir }\end{array}$ & $\begin{array}{l}\text { Guzerá } \\
\text { Guzera }\end{array}$ & $\begin{array}{c}\text { Nelore não-selecionado } \\
\text { Ordinary Nellore }\end{array}$ & $\begin{array}{c}\text { Nelore selecionado } \\
\text { Genetically improved Nellore }\end{array}$ & $\begin{array}{l}\text { Caracu } \\
\text { Caracu }\end{array}$ & $\begin{array}{l}\text { Castrado } \\
\text { Steer }\end{array}$ & $\begin{array}{c}\text { Não-castrado } \\
\text { Bull }\end{array}$ & \\
\hline $\mathrm{CC}^{1}(L C)$ & $126,68^{\mathrm{b}}$ & $126,04^{b}$ & $118,67^{\mathrm{c}}$ & $128,10^{\mathrm{b}}$ & $134,0^{\mathrm{a}}$ & $125,84^{\mathrm{a}}$ & $127,56^{\mathrm{a}}$ & 2,73 \\
\hline $\mathrm{PC}^{1}(D C)$ & $39,24^{\mathrm{b}}$ & $39,18^{\mathrm{b}}$ & $38,68^{\mathrm{b}}$ & $41,42^{\mathrm{a}}$ & $41,86^{\mathrm{a}}$ & $39,46^{\mathrm{b}}$ & $40,69^{a}$ & 2,99 \\
\hline $\mathrm{AOL}^{1}(R E A)$ & $62,20 b^{c}$ & $59,18^{\mathrm{c}}$ & $61,87 b^{c}$ & $66,04^{\mathrm{b}}$ & $73,27^{\mathrm{a}}$ & $61,38^{\mathrm{b}}$ & $67,65^{\mathrm{a}}$ & 11,98 \\
\hline
\end{tabular}

${ }^{1}$ Médias na linha, dentro de grupo genético e condição sexual, seguidas por letras diferentes, são diferentes $(P<0,05)$ pelo teste de Diferença Mínima Significativa (DMS).

${ }^{1}$ Means in a row, within genetic group and sexual condition, followed by different letters, differ $(P<0.05)$ by Least Significance Difference test (LSD).

Entre os zebuínos, os Nelore selecionados apresentaram maior valor para AOL $\left(66,04 \mathrm{~cm}^{2}\right)$, enquanto, nas demais raças, os valores se mantiveram entre 59,18 e $62,20 \mathrm{~cm}^{2} \mathrm{e}$ não diferiram entre si. Estes valores foram superiores aos relatados por Costa et al. (2005), que encontraram 53,8 e $54,6 \mathrm{~cm}^{2}$ para animais anelorados recebendo dietas com 35 e $65 \%$ de concentrado, respectivamente. Esses autores confinaram os animais com peso vivo médio inicial de $270 \mathrm{~kg}$ por apenas $100 \mathrm{dias}$, ou seja, animais leves com pouco tempo de confinamento, o que pode ter resultado em menor crescimento do músculo Longissimus dorsi.

Os animais não-castrados, em comparação aos castrados, apresentaram maior AOL $\left(67,5 \mathrm{vs} 61,38 \mathrm{~cm}^{2}\right)$, provavelmente pelo fato de a AOL ser indicativo do grau de musculosidade dos animais. Este resultado foi confirmado pela análise das variáveis TM e RMO (Tabela 4). Os valores deste estudo para AOL também foram superiores aos encontrados por Pádua et al. (2004), que, em estudo com novilhos Nelore e cruzas com Nelore, registraram $62,85 \mathrm{~cm}^{2}$ para os não-castrados e $58,30 \mathrm{~cm}^{2}$ para os castrados. Entretanto, os animais foram abatidos em idades precoces pesando 373,8 e 341, $2 \mathrm{~kg}$ (não-castrados e castrados, respectivamente), o que demonstra que o músculo Longissimus dorsi é de crescimento tardio e ainda apresenta certo desenvolvimento na fase de acabamento.

Verificou-se efeito apenas de grupo genético para espessura de gordura de cobertura (GC), de modo que os animais Caracu apresentaram as menores GC, semelhantes aos valores obtidos para a raça Gir, que, por sua vez, foram semelhantes aos encontrados para os demais zebuínos (Tabela 6). Normalmente, espera-se que animais castrados apresentem maior GC que os não-castrados, o que não foi verificado neste estudo, talvez porque os animais foram abatidos com mesmo grau de acabamento, quando apresentavam $4 \mathrm{~mm}$ de espessura de gordura de cobertura.

\section{Conclusões}

As características da carcaça de bovinos, como peso, rendimento e proporção de tecido muscular, podem ser afetadas pela condição sexual, ou seja, os animais nãocastrados produzem carcaças mais pesadas e com maior rendimento.

Ficou evidenciado a necessidade de melhoria das características de deposição de gordura e proporção de traseiro especial nos programas de melhoramento genético da raça Caracu.

Os animais do grupo genético Nelore selecionado produziram carcaças mais pesadas que o grupo não-selecionado, evidenciando melhora do processo de seleção para peso ao qual foram submetidos.

\section{Literatura Citada}

BERG, R.T.; BUTTERFIELD, R.M. New concepts of cattle growth. New York: Sydney University, 1976. 240p.

COSTA, M.A.L.; VALADARES FILHO, S.C.; PAULINO, M.F. et al. Desempenho, digestibilidade e características de carcaça de novilhos zebuínos alimentados com dietas contendo diferentes níveis de concentrado. Revista Brasileira de Zootecnia, v.34, n.1, p.268-279, 2005.

CROUSE, J.D.; DIKEMAN, M.E. Determinates of retail product of carcass beef. Journal of Animal Science, v.42, n.3, p.584$591,1976$.

CRUZ, G.M.; TULLIO, R.R.; ESTEVES, S.N. et al. Peso de abate de machos não-castrados para produção do bovino jovem. 2. Peso, idade e características de carcaça. Revista Brasileira de Zootecnia, v.33, n.3, p.646-657, 2004.

GESUALDI JR., A.; PAULINO, M.F.; VALADARES FILHO, S.C. et al. Níveis de concentrado na dieta de novilhos F1 Limousin $\mathrm{x}$ Nelore: características de carcaça. Revista Brasileira de Zootecnia, v.29, n.5, p.1467-1473, 2000. 
HAMMACK, S.P. [2001] Cattle types and breeds characteristics and uses. Disponível em: <http://stephenville.tamu.edu/ $\sim$ shammack/L5206.pdf> Acesso em: 08/06/2001.

HANKINS, O.G.; HOWE, P.E. Estimation of the composition of beef carcass and cuts. Washington: USDA, 1946. 20p. (Technical Bulletin, 926).

JORGE, A.M.; FONTES, C.A.A., PAULINO, M.F. et al. Desempenho produtivo de animais de quatro raças zebuínas, abatidos em três estádios de maturidade. 2. Características da carcaça. Revista Brasileira de Zootecnia, v.28, n.1, p.381-389, 1999.

LUCHIARI FILHO, A. Pecuária da carne bovina. São Paulo: LinBife, 2000. 134p.

MORGAN, J.B.; WHEELER, T.L.; KOOHMARAIE, M. et al. Effect of castration on myofibrillar protein turnnover, endogenous proteinase activities, and muscle growth in bovine skeletal muscle. Journal of Animal Science, v.71, n.2, p.408-414, 1993.

MÜLLER, L. Normas para avaliação de carcaças e concurso de carcaças de novilhos. Santa Maria: Universidade Federal de Santa Maria, 1987. 31p.

NARDON, R.F. Seleção de bovinos para desempenho: composição corporal e características de carcaça. Jaboticabal: Universidade Estadual Paulista, 1998. 99p. Tese (Doutorado em Zootecnia) - Universidade Estadual Paulista, 1998.

NATIONAL RESEARCH COUNCIL - NRC. Nutrients requeriments of beef cattle. 7.ed. Washington, D.C.: National Academy of Sciences, 1996. 244p.

OWENS, F.N.; DUBESKI, P.; HANSON, C.F. Factors that alter the growth and development of ruminants. Journal of Animal Science, v.71, n.6, p.3138-3150, 1993.

PÁDUA, J.T.; MAGNABOSCO, C.U.; SAINZ, R.D. et al. Genótipo e condição sexual no desempenho e nas características de carcaça de bovinos de corte superjovens. Revista Brasileira de Zootecnia, v.33, n.6, p.2330-2342, 2004 (supl. 3).

PEROTTO, D.; MOLETTA, J.L.; CUBAS, A.C. Características quantitativas da carcaça de bovinos charolês, caracu e cruzamentos recíprocos terminados em confinamento. Revista Brasileira de Zootecnia, v.29, n.1, p.117-124, 2000.
RESENDE, F.D.; NARDON, R.F.; RAZOOK, A.G. et al. Desempenho e características de carcaça de zebuínos e caracu selecionados para peso aos 378 dias de idade, submetidos a dois níveis de energia na terminação. In: REUNIÃO ANUAL DA SOCIEDADE BRASILEIRA DE ZOOTECNIA, 37., 2000, Viçosa, MG. Anais... Viçosa, MG: Sociedade Brasileira de Zootecnia/Gnosis, [2000]. CD-ROM. Nutrição de Ruminantes. 0507

RESENDE, F.D. Peso ideal ao abate. In: ENCONTRO TERRA NOVA DE PECUÁRIA, 4., 2001, Rio Preto. Anais... Rio Preto SESC - Fazenda do Instituto de Zootecnia de São José do Rio Preto, 2001. 143p.

STATISTICAL ANALYSIS SYSTEM - SAS. SAS/STAT User's guide. version 6.12. Cary: 1989, v.1. 943p.

SILVA, F.F. Aspectos produtivos da castração de novilhos de corte. Cadernos Técnicos de Veterinária e Zootecnia, n.33, p.6895, 2000

SILVA, F.F.; VALADARES FILHO, S.C.; ÍTAVO, L.C.V et al. Consumo, desempenho, características de carcaça e biometria do trato gastrintestinal e dos órgãos internos de novilhos nelore recebendo dietas com diferentes níveis de concentrado e proteína. Revista Brasileira de Zootecnia, v.31, n.4, p.1849-1864, 2002.

SILVA, D.J.; QUEIROZ, A.C. Análise de alimentos (métodos químicos e biológicos). 3.ed. Viçosa, MG: Universidade Federal de Viçosa, 2002. 235p.

Van SOEST, P.J.; ROBERTSON, J.B.; LEWIS, B.A. Symposium: carbohydrate methodology, metabolism and nutritionnal implications in dairy cattle. Journal of Dairy Science, v.74, n.10, p.3583-3597, 1991 . 